\title{
Simulated Difficult Airway: CMAC D Blade or Glidescope?
}

\author{
Mahesh Madhugiri Chandrashekaraiah ${ }^{1^{*}}$, Vijay Arjandas Sahitya ${ }^{2}$, Priti Narayan $^{3}$, Shahid Adeel $^{4}$ \\ ${ }^{1,2}$ Senior Registrar, ${ }^{3,4}$ Consultant, King Hamad University Hospital, Bahrain
}

\section{Background}

Manual in line axial stabilization (MIAS) technique is recommended for stabilizing the cervical spine in suspected cervical spine injuries, but creates special challenges in airway management. The present study compares two different video laryngoscope (VL) namely CMAC D blade (CMAC) and glidescope blade 4 (GL) for intubation in patients with a simulated difficult airway by applying MIAS.

\begin{abstract}
Methodology
This was a hospital based prospective, single blind, randomized comparative pilot study. A total of 60 patients, having no predictors of difficult airway and scheduled for elective surgery were recruited and randomized into 2 equal sized groups based on a software generated random sequence. The Primary outcome was Intubation Difficulty Score (IDS), whereas the time taken to secure the airway and obtain a capnographic wave, Cormack Lehane Grade (CL) and hemodynamic parameter comprised the secondary outcomes. The following tests- Fischer's exact test, Chi-square test and Student ' $t$ ' test used for analysis.
\end{abstract}

\section{Results}

GL group had an IDS score of zero in $46.7 \%$ patients compared to $26.7 \%$ in CMAC group, IDS score of $0-5$ was found to be $50 \%$ in GL group while CMAC group scored $66.6 \%$. This was found to be statistically insignificant ( $\mathrm{p}=0.18$ ). Time taken for successful intubation was $43.70 \pm 9.91$ and $54.60 \pm 20.47$ seconds $(\mathrm{p}=0.011)$ in GL and CMAC group respectively.

\section{Conclusions}

VL is a vital tool in the management of difficult airway. The superiority of one over the other device tested here could not be established, although GL showed slightly better scores but were statistically insignificant.

Keywords: difficult airway, video laryngoscope, CMAC, glidescope, MIAS

\section{Introduction}

The Video-laryngoscopes (VL) have become an

\section{*Correspondence: Mahesh Madhugiri \\ Chandrashekaraiah}

E mail: drmcm@rediffmail.com

(iD https://orcid.org/0000-0001-7874-6433

Received: 28/06/2020

Accepted: 06/01/2021

DOI: http:/doi.org/10.4038/slja.v29i1.8626

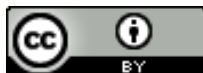

integral part of all difficult intubation guidelines. The difficult airway society in 2015 recommended VL role in managing patients with suspected difficult airway. ${ }^{1}$ The first idea of video laryngoscopy was conceived in 1995 and during the early part of this century first video laryngoscope was made commercially available. ${ }^{2}$ Manual in line axial stabilization (MIAS) is a proven technique for stabilizing cervical spine in suspected cervical spine injuries ${ }^{3}$ that can lead to difficulty in intubation. Studies ${ }^{4,5}$ done earlier appreciated the advantages of either CMAC or GL in predicted or simulated difficult airway. In this research we wanted to see the difference between the two VL namely CMAC- D blade (CMAC) and glidescope blade 4 (GL) in simulated difficult 
airway by measuring IDS and time required for intubation.

\section{Methodology}

This was a prospective, single blind, randomized comparative pilot study, conducted after obtaining institution ethics committee approval. This particular study compared CMAC- D blade with glidescope blade 4 in patients with simulated difficult airway created using MIAS maneuver. Study sample was randomized using www.randomization.com (seeding number-10207). The inclusion criteria for this study comprised of patients admitted for elective surgery requiring general anesthesia with endotracheal intubation. We included patients aged 18 years to 65 years of either sex who were of ASA 1 and 2 physical status. Other inclusion criteria comprised of mouth opening more than $4 \mathrm{~cm}$, with thyromental distance more than $6 \mathrm{~cm}$, Mallampati (MP) grade 1 and 2 with no current or previous documented evidence of difficult airway. The exclusion criteria involved trauma patients, emergency surgery, any clinical predictors of difficult airway, burn patients, bronchial asthma, COPD, bronchiectasis, and recent history of chest infection

After obtaining the written and informed consent, standardized anesthetic technique employed in both groups: pre-oxygenation for 3 minutes with $100 \%$ oxygen, induction with propofol titrated to loss of verbal response, fentanyl $2 \mathrm{mcg} / \mathrm{kg}$, and muscle relaxation achieved with atracurium $0.5 \mathrm{mg} / \mathrm{kg}$ followed by intermittent positive pressure ventilation with $100 \%$ oxygen for 3 minutes. Intubation attempt done after 3 minutes with application of MIAS maneuver by an experienced anesthetist with experience of VL for at least 3 years. Only 2 consultant anaesthetists were involved in intubation process to standardize the study and reduce bias. Intubation difficulty score (IDS) was recorded as described by Adnet ${ }^{6}$.

The trachea was intubated using appropriate size endotracheal tube using the stylet provided by the manufacturer for VL. Maintenance of anesthesia was achieved with sevoflurane with oxygen and air mixture. At the end of the procedure residual muscle relaxant was reversed with neostigmine $(0.05 \mathrm{mg} / \mathrm{kg})$ and glycopyrrolate $(0.01 \mathrm{mg} / \mathrm{kg})$. Extubation was done in awake state on spontaneous breathing after fulfillment of extubation criteria.

The following data was collected from the study population: Intubation difficulty score (IDS), Cormack Lehane (CL) grade and time taken for successful intubation as defined by cessation of positive pressure ventilation till the satisfactory end tidal carbon dioxide trace. The hemodynamic parameters include heart rate (HR), systolic blood pressure (SBP), and diastolic blood pressure (DBP) and mean arterial pressure (MAP). Failure to intubate defined as an attempt exceeding 120 seconds, more than three laryngoscopy attempts and desaturation $\mathrm{SpO}_{2}<90 \%$. Rescue methods in case of failure to intubate include bag and mask ventilation, attempts to intubation will be with the most preferred way and comfort of the laryngoscopist using any laryngoscope with the removal of MIAS. Hemodynamic parameters were recorded at following intervals pre-induction, preintubation, post intubation and post intubation 3 minutes.

Our statistician calculated the sample size based on our initial results. For an outcome variable on IDS score, with difference of 0.7 score, standard deviation of 1.40 , effect size 0.5 with $90 \%$ statistical power and 5\% significance, the sample size of 60 (30 in each group) was adequate. The following test were employed: Chi-Square test, Fisher Exact test, student ' $\mathrm{t}$ ' test.

\section{Results}

Table 1 depicts our study population $(n=60)$. The age of the study group was 30 years with average BMI $28.1 \mathrm{Kg} / \mathrm{m}^{2}$. The gender distribution was also statistically insignificant with 9 females in CMAC Group and 10 females in GL group $(\mathrm{p}=1.000)$. Table 1 also represents the airway examination: mouth opening, thyro-mental distance (TMD), sterno-mental distance and neck circumference. There is no difference between the two groups.

MP grading of our study groups is described along with CL classification in Table 2. As mentioned in inclusion criteria, we only recruited patients with MP grade 1 and grade 2. In CMAC group, we observed that $36.7 \%$ patients were of MP grade 1 
Table 1

Physical characteristics and airway examination

\begin{tabular}{|l|l|l|l|}
\hline Parameter & \multicolumn{1}{|c|}{$\begin{array}{c}\text { Group CMAC } \\
(\mathbf{3 0})\end{array}$} & \multicolumn{1}{|c|}{$\begin{array}{c}\text { Group GL } \\
(\mathbf{3 0})\end{array}$} & P value \\
\hline Age in years & $30.90 \pm 8.74$ & $30.90 \pm 8.47$ & 1.000 \\
\hline Weight $(\mathrm{kg})$ & $81.90 \pm 16.99$ & $77.85 \pm 18.40$ & 0.379 \\
\hline Height $(\mathrm{cm})$ & $169.63 \pm 9.96$ & $167.77 \pm 8.31$ & 0.434 \\
\hline BMl $\left(\mathrm{kg} / \mathrm{m}^{2}\right)$ & $28.39 \pm 4.86$ & $27.80 \pm 5.91$ & 0.674 \\
\hline $\begin{array}{l}\text { Mouth opening } \\
(\mathrm{cm})\end{array}$ & $5.00 \pm 0.66$ & $5.12 \pm 0.52$ & 0.042 \\
\hline TMD $(\mathrm{cm})$ & $8.03 \pm 1.00$ & $8.27 \pm 0.94$ & 0.357 \\
\hline $\begin{array}{l}\text { Sterna mental } \\
\text { distance(cm) }\end{array}$ & $16.02 \pm 2.18$ & $16.35 \pm 1.91$ & 0.532 \\
\hline $\begin{array}{l}\text { Neck } \\
\text { circumference } \\
\text { (cm) }\end{array}$ & $39.28 \pm 4.10$ & $38.60 \pm 4.15$ & 0.524 \\
\hline
\end{tabular}

(Student ' $\mathrm{t}$ ' test two tailed independent)

while MP grade 2 patients were $63.3 \%$. On the other hand, GL group had $46.7 \%$ patients with MP grade 1 and $53.3 \%$ were of MP grade 2. Cormack Lehane (CL) grading of glottis opening during video laryngoscopy. CL grade $1 \& 2$ constituted 96.6\% in Group CMAC and 93.3\% in Group GL. CL 3noted in two patients in group CMAC and one patient in Group GL respectively. There was no statistical significance.

Table 2

Mallampati Assessment and Cormack Lehane Grade

\begin{tabular}{|l|l|l|l|}
\hline Variable & $\begin{array}{l}\text { Group } \\
\text { CMAC }\end{array}$ & Group GL & P value \\
\cline { 1 - 3 } MP-1 & $11(36.7 \%)$ & $14(46.7 \%)$ & \multirow{2}{*}{0.430} \\
\cline { 1 - 3 } MP-2 & $19(63.3 \%)$ & $16(53.3 \%)$ & \\
\hline CL 1 and 2 & $28(93.3 \%)$ & $29(96.7 \%)$ & \multirow{2}{*}{1.000} \\
\cline { 1 - 3 } CL 3 & $2(6.7 \%)$ & $1(3.3 \%)$ & \\
\hline
\end{tabular}

(Chi-Square test)

The table 3 shows IDS score. According to the results, $46.7 \%$ cases in GL group had IDS score zero in comparison to CMAC group where only $26.7 \%$ had zero IDS score. On the other hand, mild to moderate difficulty (IDS score 0-5) was higher in CMAC group as well (66.6\%) as compared to GL group (50\%). Difficult IDS score $(>5)$ was seen in 2 patients in CMAC group, and one patient in GL group. There was no statistical significance between the study groups $(\mathrm{p}=0.180)$.
Table 3

IDS Score

\begin{tabular}{|l|l|l|}
\hline IDS Score & $\begin{array}{l}\text { Group } \\
\text { CMAC }\end{array}$ & Group GL \\
\hline No difficulty IDS Score 0 & $8(26.7 \%)$ & $14(46.7 \%)$ \\
\hline $\begin{array}{l}\text { Mild to Moderate Difficulty IDS } \\
\text { Score 0-5 }\end{array}$ & $20(66.6 \%)$ & $15(50.0 \%)$ \\
\hline Difficult IDS score >5 & $2(6.67 \%)$ & $1(3.33 \%)$ \\
\hline
\end{tabular}

(Fischer's exact test, $\mathrm{P}=0.180$ )

Time taken for intubation was another parameter taken in to account in our study and the results are shown in Table 4. Mean time taken in CMAC group was $54.67+/-20.47$ seconds and it was $43.70+/-9.97$ seconds $(\mathrm{p}=0.011)$. The difference was statistically significant.

\section{Table 4}

Time taken for successful intubation

\begin{tabular}{|l|l|l|l|c|}
\hline Variables & $\begin{array}{l}\text { Group } \\
\text { CMAC }\end{array}$ & Group GL & Total & $\begin{array}{c}\mathbf{P} \\
\text { value }\end{array}$ \\
\hline Time & $54.60 \pm 20.47$ & $43.70 \pm 9.91$ & $49.15 \pm 16.86$ & $0.011^{*}$ \\
\hline
\end{tabular}

(Student ' $\mathrm{t}$ ' test independent 2 tailed)

Secondary hemodynamic parameters such as heart rate (HR), Systolic blood pressure (SBP), diastolic blood pressure (DBP) and mean arterial pressure (MAP)were measured and are shown in Table 5. There was no striking difference noted between both study groups.

\section{Table 5}

Hemodynamic Parameters

\begin{tabular}{|l|l|l|l|l|}
\hline $\begin{array}{l}\text { Heart Rate } \\
\text { (bpm) }\end{array}$ & Group CMAC & Group GL & Total & $\begin{array}{c}\text { P } \\
\text { value }\end{array}$ \\
\hline Pre-induction & $83.20 \pm 12.39$ & $87.00 \pm 18.63$ & $85.10 \pm 15.80$ & 0.356 \\
\hline Pre-Intubation & $79.00 \pm 8.96$ & $77.50 \pm 14.54$ & $78.25 \pm 11.99$ & 0.632 \\
\hline Post intubation & $88.13 \pm 14.13$ & $90.60 \pm 18.33$ & $89.37 \pm 16.28$ & 0.562 \\
\hline $\begin{array}{l}\text { Post intubation } \\
3 \text { min }\end{array}$ & $84.67 \pm 12.04$ & $79.17 \pm 18.57$ & $81.92 \pm 15.76$ & 0.179 \\
\hline
\end{tabular}

\begin{tabular}{|l|l|l|l|c|}
\hline SBP (mm Hg) & $\begin{array}{l}\text { Group } \\
\text { CMAC }\end{array}$ & Group GL & Total & $\begin{array}{c}\text { P } \\
\text { value }\end{array}$ \\
\hline Pre-induction & $\begin{array}{l}135.63 \pm 16 . \\
04\end{array}$ & $135.60 \pm 15.26$ & $135.62 \pm 15.52$ & 0.993 \\
\hline Pre-Intubation & $\begin{array}{l}107.80 \pm 18 . \\
97\end{array}$ & $105.30 \pm 13.99$ & $106.55 \pm 16.58$ & 0.564 \\
\hline Post intubation & $\begin{array}{l}124.90 \pm 21 . \\
35\end{array}$ & $112.90 \pm 17.98$ & $118.90 \pm 20.48$ & 0.022 \\
\hline $\begin{array}{l}\text { Post intubation } \\
3 \text { min }\end{array}$ & $\begin{array}{l}106.10 \pm 12 . \\
72\end{array}$ & $103.13 \pm 13.41$ & $104.62 \pm 13.04$ & 0.383 \\
\hline
\end{tabular}




\begin{tabular}{|l|l|l|l|c|}
\hline DBP $(\mathbf{m m} \mathrm{Hg})$ & Group CMAC & Group GL & Total & $\begin{array}{c}\text { P } \\
\text { value }\end{array}$ \\
\hline Pre-induction & $81.97 \pm 11.99$ & $79.50 \pm 13.91$ & $80.73 \pm 12.94$ & 0.465 \\
\hline Pre-Intubation & $63.37 \pm 20.13$ & $56.67 \pm 10.15$ & $60.02 \pm 16.17$ & 0.109 \\
\hline Post intubation & $77.57 \pm 17.20$ & $68.03 \pm 16.59$ & $72.80 \pm 17.43$ & 0.033 \\
\hline $\begin{array}{l}\text { Post intubation } \\
3 \text { min }\end{array}$ & $60.63 \pm 13.55$ & $58.53 \pm 13.47$ & $59.58 \pm 13.44$ & 0.550 \\
\hline
\end{tabular}

\begin{tabular}{|l|l|l|l|c|}
\hline MAP (mm Hg) & Group CMAC & Group GL & Total & $\begin{array}{c}\text { P } \\
\text { value }\end{array}$ \\
\hline Pre-induction & $98.13 \pm 12.23$ & $97.47 \pm 11.58$ & $97.80 \pm 11.81$ & 0.829 \\
\hline Pre-Intubation & $77.67 \pm 18.46$ & $73.07 \pm 9.62$ & $75.37 \pm 14.78$ & 0.231 \\
\hline Post intubation & $94.20 \pm 17.21$ & $84.83 \pm 15.56$ & $89.52 \pm 16.94$ & 0.031 \\
\hline $\begin{array}{l}\text { Post intubation } \\
3 \text { min }\end{array}$ & $75.73 \pm 11.91$ & $73.40 \pm 12.80$ & $74.57 \pm 12.31$ & 0.468 \\
\hline
\end{tabular}

(Student ' $\mathrm{t}$ ' test independent test)

\section{Discussion}

The results of our study emphasize the effectiveness of video laryngoscopy in the difficult airway situations. Our study reveals that there was no statistical significance in IDS score $(p=0.180)$ between the two groups; however, GL group had zero IDS score in $46.7 \%$ cases when compared with CMAC group constituting only $26.7 \%$. Another finding of our study was the time required for successful intubation, as defined in methodology, was less in GL group with mean of 43.7 seconds in comparison to 54.67 seconds in CMAC group $(p=0.011)$. The hemodynamic parameters were more or less similar in both the groups.

Kumar et $\mathrm{al}^{7}$ reported no difference in IDS score between glidescope and CMAC D blade when used in patients with cervical spine pathology, who required MIAS maneuver. Only 5 patients in glidescope group and one patient in CMAC group had IDS score more than zero in their study, depicting easy intubations with both the devices. However, in our study we had more cases with high IDS score in both the group, 22 (73.3\%) patients in CMAC and 16 (53.3\%) patients in GL group contradicting their findings.

In a study done by Elwain ${ }^{8}$ and Laffey on 90 patients with use of manual in line cervical stabilization, the airtraq laryngoscope reduced the IDS score, improved the CL glottis view, and also reduced the need for optimization maneuvers, in comparison to both Macintosh and C-MAC laryngoscope. However, there were no differences in success rates or hemodynamic profiles post intubation between any of the devices tested. Our study also has similar findings in terms of success rates. The shape of the glidescope AVL blade (Verathon Inc, USA) TM. has hyper angle 60degree curve. ${ }^{9}$ This angle helps in indirect visualization of anterior larynx with ease. It is recommended to use preformed stylet supplied by the manufacturer while using glidescope.

CMAC-D blade (Karl, Storz, Tuttingen, Germany) TM was developed in cooperation with Prof. Dr. Volker Dörges. ${ }^{2,10}$ It is unique in that it is an elliptical shaped blade rising distally making nearly a half moon curve. ${ }^{10}$ The CMAC- D blade also has 40-degree angulation. ${ }^{11}$

M Kleine et $\mathrm{al}^{5}$ published one multicenter study involving 720 patients. This study used six available video laryngoscopes, three channeled and three unchannelled. They found out that first attempt success rate was high with CMAC D blade and Mc Grath followed by the King vision, glidescope and airtraq respectively. E Cavus et al ${ }^{12}$ reported similar findings to our study in elective cases that require general anesthesia with endotracheal intubation but no MIAS was applied. Mohamed Zaini ${ }^{13}$ and team did a similar study using cervical semi rigid collar, testing CMAC- D blade and glidescope ranger. Although they reported improved glottis view in both the groups, CMAC D blade outperformed in both view and time taken for intubation. However, our study shows lesser time in glidescope as compared to CMAC with no statistical significance.

M F Aziz ${ }^{14}$ and colleagues in their secondary analysis of a multicenter randomized study using CMAC- D blade and glidescope noted that the experience of laryngoscopist, type of surgery, mouth opening and position of the patient affects the difficulty in acute video-laryngoscopy. Notably, amongst these factors at least two are modifiable. Our study compared CMAC D blade and glidescope blade 4. Although several studies 3,4,7,15-19 done earlier appreciated the benefits of either CMAC or glidescope, our study revealed that glidescope slightly out performs the CMACD blade in terms of zero IDS. However, there was no clinical significance or statistical significance if 
we compare IDS score altogether $(\mathrm{p}=0.180)$. There are few intrinsic limitations in our study. The IDS score is subjective, and based on the operator. In order to minimize the bias only 2 senior anesthetists with experience in VL did the laryngoscopy. The time taken for successful intubation as defined in our study can also have recording bias.

\section{Conclusions}

The video laryngoscopes have been in operation for almost decade and a half. When it comes for comparative assessment, we believe the present study didn't decisively conclude superiority of the two devices tested. However, GL group has slight edge over in terms of time required for intubation.

\section{Acknowledgements}

Dr KP Suresh, PhD

Bio-Statistician Principal Scientist

National Institute of Veterinary Epidemiology and Disease Informatics (NIVEDI)

Post Box 6450Yelahanka, Bangalore-560064 0091- 080-28390183

\section{References}

1. Frerk C, Mitchell VS, McNarry AF, Mendonca C, Bhagrath R, Patel A, et al. Difficult Airway Society intubation guidelines working group. Difficult Airway Society 2015 guidelines for management of unanticipated difficult intubation in adults. $\mathrm{Br} J$ Anaesth. 2015; 115(6): 827-48.

2. Serocki and Volker Dorges. History of videolaryngoscopy. In: Volker Dorges editors. The CMAC Video-laryngoscopy system in clinical and emergency medicine 2nd ed. Germany: Endo Press GMBH; 2015. pp. 16-17

3. Hiboutot, F., Nicole, P.C., Trépanier, C.A. Turgeon Af, Lessard MR. Effect of manual in-line stabilization of the cervical spine in adults on the rate of difficult orotracheal intubation by direct laryngoscopy: a randomized controlled trial. Can J Anesth. 2009; 56: 412-418.

4. DabounAbd-Elfattah M, Ismail Ezz El-Din F, HamzawyHassanain A, Emara Ayman S Feasibility and outcome of GlideScope videolaryngoscope versus C-MAC video-laryngoscope in the management of obese patients with potentially difficult intubation. Ain Shams Jour Anesth 2017; 10(1): 164-172

5. M. Kleine-Brueggeney, R. Greif, P. Schoettker, G. L. Savoldelli, S. Nabecker, L. G. Theiler. Evaluation of six videolaryngoscopes in 720 patients with a simulated difficult airway: a multicenter randomized controlled trial. $\mathrm{Br} J$ Anaesth 2016; 116 (5): 670-9

6. Frederic Adnet, Stephen W. Borron, Stephane X. Racine, Jean-Luc Clemessy, Jean-Luc Fournier, Patrick Plaisance, Claude Lapandry The Intubation Difficulty Scale (IDS): Proposal and Evaluation of a New Score Characterizing the Complexity of Endotracheal Intubation. Anesthesiology 1997; 87(6): 1290-1297

7. Kumar D, Gombar S, Ahuja V, Malhotra A, Gupta S. GlideScope versus D-blade for tracheal intubation in cervical spine patients: A randomised controlled trial. Indian J Anaesth 2019; 63: 544-50.

8. McElwain J, Laffey JG. Comparison of the CMAC®, Airtraq ${ }^{\circledR}$, and Macintosh laryngoscopes in patients undergoing tracheal intubation with cervical spine immobilization. Br J Anaesth 2011 ;107(2): 258-64

9. Emily R. Bacon,MS Michael P. Phelan, D. John Doyle,Tips and Troubleshooting for Use of the GlideScope Video Laryngoscope for Emergency Endotracheal Intubation. Am J Emerg Med. 2015; 33(9): 1273-7

10. Xue FS, Li HX, Liu YY, Yang GZ. Current evidence for the use of C-MAC videolaryngoscope in adult airway management: a review of the literature. Ther Clin Risk Manag 2017; 7(13): 831841 .

11. S.B Shah, U Harihharan, AK Bhargava C Mac D blade: Clinical tips and tricks. Trends in Anaesthesia and Critical Care. 2016; 6: 6-10

12. E. Cavus, T. Neumann, V. Doerges, B. Bein, G. SerockiA Randomized, Crossover Comparison of C-Mac D-blade, Glidescope, and Conventional Macintosh Laryngoscopy During Routine Induction of Anesthesia. Annal Emer Med 2010; 56(3): S25

13. Mohamad Zaini, R. H., Che Wil, F. F. Wan Hassan, W. N. Ibrahim, M. I. Comparison of the Effectiveness Between C-Mac D-Blade and Glidescope Ranger for Tracheal Intubation in Simulated Patient with Cervical Spine Immobilization. Anesthesia \& Analgesia. 2016; 123: 695

14. M. F. Aziz, E. O. Bayman, M. M. Van Tienderen, M. M. Todd, A. M. Brambrink. Predictors of difficult videolaryngoscopy with GlideScope ${ }^{\circledR}$ or C-MAC® with D-blade: secondary analysis from a large comparative video laryngoscopy trial. $\mathrm{Br} J$ Anaesth 2016; 117 (1): 118-23

15. M M Chandrashekaraiah, V H Shah, V C Pandey, $\mathrm{S}$ Adeel Evaluation of ease of intubation using CMAC vs Macintosh laryngoscope in patients with the application of manual inline axial stabilization - A randomized comparative study. Sri Lankan Journal of Anaesthesiology 2017; 25(1): 8-12 
16. Erol Cavus, Tobias Neumann, Volker Doerges, Thora Moeller, Edwin Scharf, Klaus Wagner, et al. First Clinical Evaluation of the C-MAC D-Blade Video-laryngoscope During Routine and Difficult Intubation. Anesthesia \& Analgesia 2011; 112 (2): 382-385

17. D. Cattano, R. M. Corso, A. V. Altamirano, C. B. Patel, M. M. Meese, C. Seitan, C. A. Hagberg. Clinical evaluation of the C-MAC D-Blade videolaryngoscope in severely obese patients: a pilot study. Br J Anaesth 2012; 109(4): 647-648
18. Alper Kılıçaslan, Ahmet Topal, Atilla Erol, Sema Tuncer Uzun. Comparison of the C-MAC D-Blade, Conventional C-MAC, and Macintosh Laryngoscopes in Simulated Easy and Difficult Airways. Turk J Anaesth Reanim 2014; 42: 182185

19. Aziz MF, Healy D, Kheterpal S, Fu RF, Dillman D, Brambrink AM. Routine clinical practice effectiveness of the Glidescope in difficult airway management: an analysis of 2,004 Glidescope intubations, complications, and failures from two institutions. Anesthesiology. 2011; 114(1): 34-41 